\title{
Establishing an academic niche in cardiothoracic surgery: The earlier the better
}

Garrett Coyan, MD, MS, Leonid Emerel, MD, and Christopher Sciortino, MD, PhD

\author{
From the Department of Cardiothoracic Surgery, University of Pittsburgh Medical Center, Pittsburgh, Pa. \\ Disclosures: Authors have nothing to disclose with regard to commercial support. \\ Received for publication Sept 20, 2018; revisions received Nov 2, 2018; accepted for publication Nov 12, 2018; \\ available ahead of print Dec 29, 2018. \\ Address for reprints: Garrett Coyan, MD, MS, Department of Cardiothoracic Surgery, UPMC Presbyterian Hos- \\ pital, 200 Lothrop St, Suite F441, Pittsburgh, PA 15213 (E-mail: coyangn@upmc.edu). \\ J Thorac Cardiovasc Surg 2019;157:2381-4 \\ $0022-5223 / \$ 36.00$ \\ Copyright (C) 2018 by The American Association for Thoracic Surgery \\ https://doi.org/10.1016/j.jtcvs.2018.11.040
}

\section{THE NEED FOR A RESEARCH NICHE}

Academic cardiothoracic surgery has undergone a significant transformation over the last several decades. Although clinical demands and administrative responsibilities have increased to care for an ailing and elder patient population, the surgeon workforce continues to decline. Research funding has also progressively become more difficult to secure, whereas the research techniques have become more complex and expensive to perform. These constraints have limited the available bandwidth for surgeons to contribute to new discovery and innovation.

Despite these challenges, cardiothoracic surgeons can and should still occupy a unique position at the forefront of clinical and scientific discovery. The academic cardiothoracic surgeon of the future will indeed look very different from those of our predecessors and mentors. A critical part of this transition and transformation will be acquiring the experience and training necessary to conduct innovative discovery within our field, given the modern research environment. This process requires a significant time commitment above and beyond the surgeon's clinical practice. Because of the nature of multidisciplinary teams and broad knowledge base required for scientific discovery, a well-protected opportunity to invest in research opportunities in the very early stages of surgeon development is necessary to achieve academic success. We believe developing a research niche as early as possible is a key stepping stone to building a successful career in academic cardiothoracic surgery today.

\section{EARLY MENTORED RESEARCH ENVIRONMENT IS CRITICAL}

Most cardiothoracic surgery residents $(76 \%$ according to a recent survey) plan to conduct research as a part of their career pathway in cardiothoracic surgery. ${ }^{1}$ Importantly, that same study demonstrated that previous participation in clinical research during residency, as well as a desire for an academic practice environment, were significant

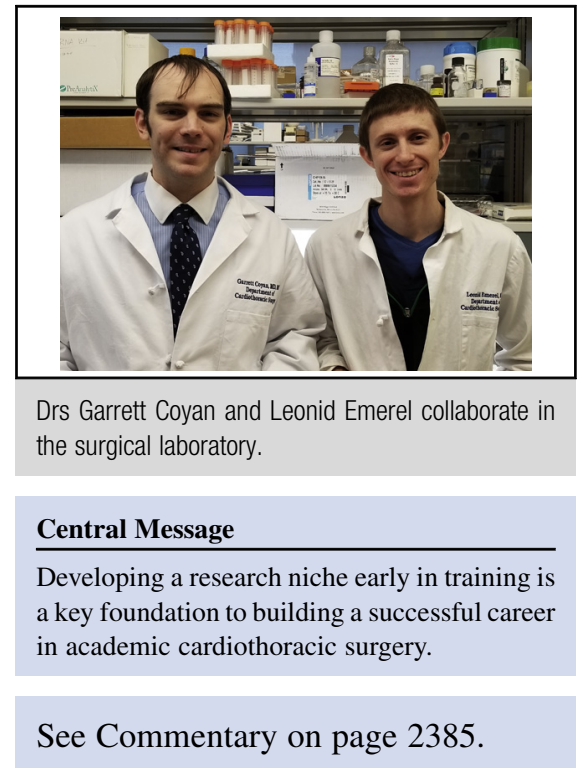

predictors of a career involving research production. Surveys from academic surgical programs have shown that those graduates who requested research time during their residency training are significantly more likely to hold academic positions after completion of residency. ${ }^{2}$

Despite this enthusiasm among residents, the skills and experiences required to transition from simply participating in a research project to becoming a primary investigator require an environment built around developing clinician-scientists with mentors who are experienced in this process. The mentored research environment for early cardiothoracic surgery trainees should involve a program that takes responsibility for guiding residents through the progression of developing an idea into a completed research project, including appropriate deliverables (manuscripts, grants, patents, and presentations as applicable). Dedicated mentored research programs have been shown in other specialties to improve both production quantity and quality in trainee research. ${ }^{3}$ Encouraging collaboration among trainees involved in research also leads to important early skill development in collaborative science, which is imperative in the increasingly complex environment of scientific discovery. In addition, working through these early peer-to-peer interactions and collaborations in a mentored setting to complete a research project instills important research ethical principles, including understanding of authorship guidelines, conflict and time management, and research reporting guidelines. Indeed, 
collaborative trainee research programs with biweekly group research meetings have resulted in increased resident research productivity. ${ }^{4}$

A supportive mentored research environment for trainees and early faculty should not be limited to interactions with other faculty/staff within cardiothoracic surgery. Research training, especially techniques to succeed in today's highpressure research environment, are unfortunately not part of standard curricula in medical school or residency. Advanced (or even basic) statistical analysis techniques, scientific writing, grantsmanship, laboratory/personnel management, and scientific/clinical study design are either given cursory treatment or completely omitted from many educational environments.

Cardiothoracic surgeons and residents should advocate for the inclusion of these topics in medical education and residency training with the same attention as is given to technical training to prepare for a successful transition to practice no matter the declared field of study. Specific educational programs dedicated to training in these important fields should be available to residents interested in an academic career. Master's degrees in public health, clinical and translational research, health policy and management, and medical product engineering/innovation are wellrepresented at academic institutions throughout the country, and relatively easy to fold into a dedicated resident research period of 1 to 2 years. Residents wishing to pursue PhDs in a related field should also receive support from a mentored research environment and mentors with appropriate experience. These advanced educational opportunities will position early researchers for successful transition to independent research and early funding success. Trainees who are seeking a career in academic surgical research should take it upon themselves to seek out residency training programs that offer a strong mentored research environment, availability of advanced training programs (such as those listed), and availability of resources to support resident education and pursuit of these important developmental activities.

\section{As Experience Is Gained, Continue to Narrow Research Focus}

In the early stages of training in academic research, it is important to keep an open mind and participate in many types of research (basic science, clinical/health services outcomes, translational science) to develop skills specific to each area and determine level of interest. At the start, it is important to say "yes" to offers from knowledgeable mentors who offer a research experience even if it is in an unfamiliar or in an antecedent field of study. No matter the project topic, learning how the research process proceeds and the organizational structure behind it is invaluable and will aid in academic growth. However, as more experience is gained (both in research and in clinical realms), narrowing the focus of research efforts is imperative.

As more senior residents and junior faculty develop areas of clinical interest either during standard training or within the context of advanced fellowships, this process may occur very naturally by shifting into a research paradigm centered around a topic of interest. As recent data support subspecialization in terms of procedures, focusing research efforts on the entire disease process that a surgeon treats may be the favorable strategy. Others may find limiting their focus to big data/outcomes research, surgical physiology, costs/ benefit analysis, or another research "paradigm" may be best suited for their interests and experiences. This is an individualized process that requires introspection on the part of the clinician-scientist to assess skill, knowledge, interest, time commitment, and support from peers. ${ }^{5}$ Narrowing the young researcher's focus allows for the early development and recognition of expertise in an area that may yield fruitful results for not only the investigator but the field as a whole. The development of this niche will result in improved strategies in idea development and implementation, a more cohesive stream of research products, and more pragmatically a clearer pathway for funding of protected research activities. The ability to synthesize a precise research strategy based on a specific niche is important to obtaining developmental funding for further training and has proven successful within our own field. ${ }^{6}$ This sets young cardiothoracic surgeon-scientists up for a transition into the role as a primary investigator early in their careers, which is necessary to establish research credibility and funding success in this difficult research environment.

\section{EARLY CAREER SURGEONS MUST LEVERAGE TRAINING EXPERIENCES TO DEVELOP RESEARCH STRATEGY}

As training concludes, surgeons wishing to pursue research need to leverage their earlier experiences to establish an independent research strategy. Borrowing from the business community, the early clinician-scientists should take the time to develop an individual research strategy based on the following strategy concepts: where do you conduct research, what value/skill do you bring, what resources will you use, and how do you sustain value/productivity. If successful narrowing of research interests has occurred as discussed previously, then determining what area of research you will "compete" in should already be clear. If a research niche has not yet been developed, junior faculty should work with a senior faculty mentor to develop of area of expertise and focus. This is paramount to articulating the goals of the research team for peers, funding sources, and practice leadership/administration. The area of research concentration should be adequately innovative to ensure that it will provide for longer-term research endeavors and be suitable for subdivision into smaller project 
units. The importance of striving for true innovation as opposed to small interval gains cannot be emphasized enough when strategizing for a long-term research paradigm as we discussed in a recent article, as concentration on interval gain projects is less likely to sustain a career, less likely to attract funding sources, and less likely to make significant gains in knowledge (https://www.aasurg. org/blog/from-research-to-innovation-a-call-to-arms-foryoung-surgeons/).

An honest assessment of the skill and value possessed by the early clinician-scientist is important when developing the research strategy. Articulating to senior leadership, mentors, and funding sources your educational and training background and highlighting pertinent research and resource management skills is important to obtain resources for establishing the young surgeon as a primary investigator. Early mentored developmental experiences and publication record should support this process. Residency and junior faculty academic productivity is directly related to midterm and late success in academic surgery, so leveraging experiences as early as possible is necessary in today's research environment. ${ }^{7}$ As most early surgeon-scientists will have some gaps in expertise, it is important to fill those gaps with support from mentors strong in those areas. In addition, collaboration with professional researchers is becoming more important than ever for those interested in true foundational basic science/engineering research. ${ }^{8}$

Obtaining adequate resources to initiate a research program is one of the most important activities for the early career academic surgeon. When initially looking for employment, discussion of research start-up packages including laboratory space, funding for capital equipment/ staff, and current research center resources is key. Assessing the academic environment of the institution is also important. Questions to consider: (1) Does the institution have a clinical/translational science institute? (2) Is there an innovation hub for managing technology transfer/intellectual property? (3) Are there adequate facilities for preclinical animal studies and basic science? (4) Is machine learning/ artificial intelligence being used for outcomes research? All of these may be important to a newly independent surgeon, and access to these resources should be explicitly outlined in a contract if applicable. In addition, seed funding and protected time should be clearly delineated as part of the contract process. Early investigators at large research centers should also discuss the possibility of early investigator mentored research awards (eg, National Institutes of Health $[\mathrm{NIH}] \mathrm{K}$-awards) for those that may benefit from intense mentored research training as early faculty.

Developing an initial research strategy that will provide sustained productivity can be challenging. However, with the development pathways we have outlined, planning for the future should come more naturally. One of the largest issues facing research sustainability early in a surgeon's career is funding support. It is well-documented that funding classically provided by the NIH has been increasingly difficult to obtain, especially for new surgeon investigators. ${ }^{10}$ This is despite the NIH's efforts to fund new investigators in general. Alternative funding sources for early investigators to sustain research must be employed to develop the track record to leverage larger NIH and nonprofit funding. Investigator seed funds, collaborator/ mentor funding, institutional start-up awards, clinical and translational research funding, and other smaller awards are ripe for filling this gap. For example, the Thoracic Surgery Foundation has established a very successful track record for funding trainee and early surgeon scientists in cardiothoracic surgery. ${ }^{11}$ Competing for these awards improves the early surgeon's grantsmanship and the ability to properly synthesize and convey research goals, and relying on the support of senior mentors and research collaborators to help with the process is invaluable to obtain the resources needed to sustain innovative research endeavors.

\section{CONCLUSIONS}

We have described a general paradigm for creating the ideal groundwork and environment for development of successful surgeon-scientists in academic cardiothoracic surgery. No doubt several instances exist in which circumstances will necessitate deviation from some of these pathways. However, the general process we describe is a rubric toward addressing the many challenges facing early academic cardiothoracic surgeons today. ${ }^{12}$ Dr Loor recently authored a blog article for the Society of Thoracic Surgeons describing clinical niche development in early career (https://www.sts.org/resources/career-resources/blog/findingniche). We believe the same type of approach should be applied specifically to the academic research portion of our field to maximize the chances for both success of the surgeon and addition of meaningful scientific innovation in cardiothoracic surgery. Although this pathway is not for everyone and keeping in mind the impending predicted shortage of cardiothoracic surgeons, we believe that for our field to progress that those who wish to make research an integral part of their career will benefit greatly from investments in early development of a research niche. This will allow cardiothoracic surgeons to continue to position themselves as leaders of the clinical and scientific teams that have a positive effect on all our patients.

\section{References}

1. Stephens EH, Shah AA, Robich MP, Walters DM, DeNino WF, Aftab M, et al The future of the academic cardiothoracic surgeon: results of the TSRA/TSDA in-training examination survey. Ann Thorac Surg. 2016;102:643-50.

2. Dunn JCY, Lai ECK, Brooks CM, Stabile BE, Fonkalsrud EW. The outcome of research training during surgical residency. J Pediatr Surg. 1998;33:362-4.

3. Torres D, Gugala Z, Lindsey RW. A dedicated research program increases the quantity and quality of orthopaedic resident publications. Clin Orthop Relat Res. 2015;473:1515-21. 
4. Brackmann M, Reynolds RK, Uppal S, McLean K. Association of a biweekly research workgroup with enhanced resident research productivity. Obstet Gynecol. 2016;128:617-20.

5. Verrier ED. Getting started in academic cardiothoracic surgery. J Thorac Cardiovasc Surg. 2000;119:S1-10.

6. Narahari AK, Charles EJ, Mehaffey JH, Walters DM, DeNino WF, Aftab M, et al Cardiothoracic surgery training grants provide protected research time vital to the development of academic surgeons. J Thorac Cardiovasc Surg. 2018;155: 2050-6.

7. Rosati CM, Koniaris LG, Molena D, Blitzer D, Su KW, Tahboub M, et al. Characteristics of cardiothoracic surgeons practicing at the top-ranked US institutions. J Thorac Dis. 2016;8:3232-44.
8. Carrel T. The relationship between surgeon and basic scientist. Transpl Immunol. 2002;9:331-7.

9. Brock MV, Bouvet M. Writing a successful NIH mentored career development grant (K award): hints for the junior faculty surgeon. Ann Surg. 2010;251:1013-7.

10. Narahari AK, Mehaffey JH, Hawkins RB, Charles EJ, Baderdinni PK, Chandrabhatla AS, et al. Surgeon scientists are disproportionately affected by declining NIH funding rates. J Am Coll Surg. 2018;226:474-81.

11. Jones DR, Mack MJ, Patterson GA, Cohn LH. A positive return on investment: research funding by the thoracic surgery foundation for research and education (TSFRE). J Thorac Cardiovasc Surg. 2011;141:1103-6.

12. Kron I, Verrier E. Developing academic cardiothoracic surgeons. J Thorac Cardiovasc Surg. 2001;121:S1-2. 